Original Article

\title{
Functional Capacity of Oldest Old Living in a Long-stay Institution in Rio De Janeiro, Brazil
}

\author{
Fabiano Moura Dias ${ }^{1,2)}$, Susana Ortiz Costa ${ }^{1)}$, Jeter Pereira de Freitas ${ }^{1)}$, \\ Adriana da Costa Rocha Pinto ${ }^{1)}$, Patrícia dos Santos Vigáriol), \\ Míriam Raquel Meira Mainenti ${ }^{1 *}$ \\ 1) Augusto Motta University Center (UNISUAM): Praça das Nações, 34, 3rd floor. Bonsucesso, Rio de \\ Janeiro, 21.041-010, Brazil \\ 2) São Camilo University Center, Brazil
}

\begin{abstract}
Purpose] A significant increase in the number of oldest old has occurred worldwide. The aim of this study was to characterize the functional capacity of the oldest old residents in a long-stay institution in Rio de Janeiro, Brazil. [Subjects and Methods] All participants were evaluated according to the following metrics: anthropometry, body composition (bioelectrical impedance), handgrip strength, balance (Berg scale and stabilometry), ankle mobility (electrogoniometry), physical capacity (six-minute walk test), quality of life (WHOQOL-OLD), and dietary habits (questionnaire). [Results] Twenty elderly subjects with a mean age of $85.75 \pm 5.22$ years and a mean fat percentage of $39.02 \pm 5.49 \%$ participated in the study. The group at risk of falls $(n=8)$ had a lower handgrip strength and walked a shorter distance over the course of six minutes compared with the group not at risk of falls. The obese group $(n=15)$ had higher values for stabilometric variables than the nonobese group. There was a positive and significant correlation between ankle joint mobility and physical capacity $(r=0.47)$. [Conclusion] High values for obesity and low values for handgrip strength and physical capacity were associated with worse body balance. Low values for ankle mobility were also associated with worse physical capacity in this population.

Key words: Elderly, Functional capacity, Institutionalization
\end{abstract}

(This article was submitted Dec. 17, 2013, and was accepted Jan. 30, 2014)

\section{INTRODUCTION}

The increase in life expectancy is a global phenomenon resulting from the improvements in social, economic, and cultural conditions that have occurred in recent decades, which have contributed to a decline in mortality and fertility and thereby increased the life expectancy of the population $^{1)}$. According to the World Health Organization (WHO), in developing countries, people over 60 years of age are considered elderly ${ }^{1}$. In Brazil, it is estimated that approximately $12 \%$ of the population is the elderly. By 2025 , this percentage is expected to increase significantly such that Brazil will rank sixth among countries with the highest numbers of elderly persons ${ }^{1,2)}$.

As a result of an increase in life expectancy, there is a new subgroup of elderly, the very elderly or the oldest old, who are more than 80 years of age. Average life expectancies above 80 years have been reported for Japan, Australia, Singapore, Switzerland, and Sweden ${ }^{3}$. The Brazilian population pyramids for 1991 to 2010 show an important

*Corresponding author. Míriam Raquel Meira Mainenti (Email: miriam.mainenti@hotmail.com)

(C2014 The Society of Physical Therapy Science. Published by IPEC Inc. This is an open-access article distributed under the terms of the Creative Commons Attribution Non-Commercial No Derivatives (by-ncnd) License $<$ http://creativecommons.org/licenses/by-nc-nd/3.0/> . tendency for population of oldest old people to increase, with this population currently representing $1.5 \%$ of the entire population of the country ${ }^{1)}$. However, it is noteworthy that this quantitative increase in the duration of life does not necessarily imply good quality of life during aging.

Matsudo et al. ${ }^{3)}$ and Navarro et al. ${ }^{4)}$ expressed concern about the global growth of the elderly population because an increase in life expectancy also results in a greater probability of chronic diseases that can potentially lead to disabilities. Aging is accompanied by changes in various body systems, such as loss of visual ${ }^{5)}$ and hearing acuity ${ }^{6}$; increases in obesity ${ }^{7}$; decreases in lean mass ${ }^{8)}$ and body flexibility $^{9}$, muscle strength ${ }^{9)}$, and cardiopulmonary performance ${ }^{10)}$; and increases in muscle fatigue ${ }^{11)}$. In addition, aging has a negative impact on physical well-being, mood, self-esteem, and body image ${ }^{12)}$, resulting in anxiety ${ }^{13)}$ and depression $^{14)}$

These changes influence mobility, stability, and balance, leading to a gradual decline in the performance of physical activities and an increase in the susceptibility to falls ${ }^{15)}$. Fabrício et al. ${ }^{16)}$ stated that all individuals are susceptible to falls, but falls are much more important in older people because they can lead to death. Therefore, it is necessary to promote public policies that encourage the elderly to perform physical activities regularly because these activities intervene in the physiological processes of aging.

Aging, with its many repercussions on health, leads to greater expenditures, which are borne by the economically 
active portion of the population. This shift in expenditures changes the productive structure of a nation and reflects a dynamic failure ${ }^{17)}$. Thus, there is a tendency to increase the number of long-stay institutions (LSIs) for the elderly ${ }^{18}$, and it is estimated that the number of institutionalized elderly in Brazil will increase from 1.3 to 4.5 million by $2060^{19)}$.

An LSI is considered to be an organizational social system intended to take care of the elderly in circumstances such as absence of the family, conditions of neglect, or lack of financial resources ${ }^{20)}$. Telarolli Júnior et al. ${ }^{21)}$ emphasize that the alternative of institutionalizing the elderly should always be considered an exception because in most cases it has disadvantages, such as distance from the family, loss of individuality, lack of social participation, isolation, and increasing physical and mental inactivity, which have negative consequences on quality of life.

The relationship between population aging and institutionalization of the elderly is a topic that is rarely addressed in the literature ${ }^{21)}$ and to which society should be attentive. To better understand this new social demand, there is a need to further investigate the factors that influence the lives of the oldest old. Therefore, the aim of this study was to describe the functional capacity-related characteristics, such as body composition, body balance, submaximal physical capacity, and quality of life, of the oldest old adults living in an LSI in Rio de Janeiro, Brazil. This investigation might contribute to development of preventive and therapeutic interventions to adequately preserve or enhance the quality of life of these people, especially those who live in LSIs.

\section{SUBJECTS AND METHODS}

This cross-sectional study was conducted in a longstay institution (LSI) in Rio de Janeiro, Brazil, and proposed by Augusto Motta University Center (UNISUAM). It was approved by the local Ethics Committee (CAAE: 04539912.4.0000.5235). Every oldest old resident of the LSI was invited to participate in this study during a lecture. Subsequently, the interested elderly were enrolled individually after they signed a consent form. The exclusion criteria were poor cognitive functioning, inability to walk, and presence of uncontrolled diseases and neuropsychiatric crises. This information was obtained from the medical department of the LSI.

The evaluation protocol was divided into three blocks with an interval of approximately seven days (ranging from five to nine days) between them (Fig. 1).

Block 1: First, we administered the Mini-Mental State Examination test (MMSE) ${ }^{22}$ to identify subjects who would be excluded due to cognitive impairment (scores under 25 and 19 for literate and illiterate, respectively), which was followed by an interview to evaluate demographic characteristics. To determine general muscle strength ${ }^{23)}$, handgrip strength was assessed using a hydraulic dynamometer (Jamar, Sammons Preston, Bolingbrook, IL, USA), with the participant in a sitting position and performing finger flexion on the dynamometer with maximal strength. The protocol was repeated three times on each hand, with a one-minute interval between trials, and the highest value

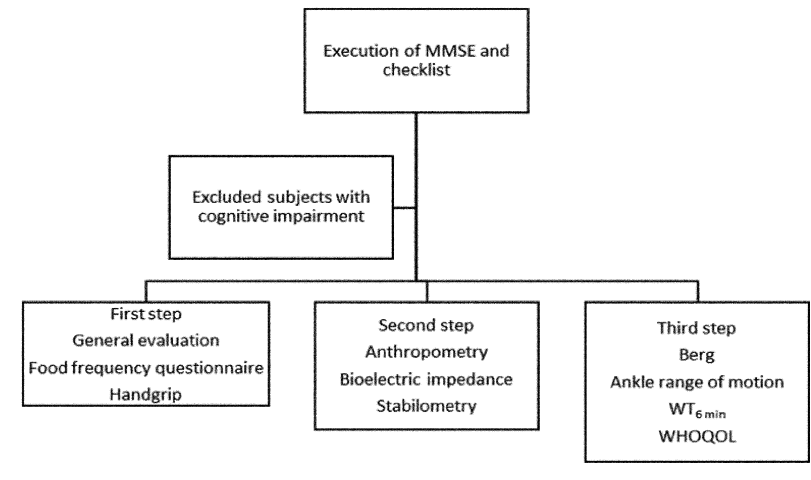

Fig. 1. Study assessments flowchart MMSE, Mini-Mental State Examination; $\mathrm{WT}_{6 \text { min }}$, Sixminute walk test; WHOQOL, World Health Organization Quality of Life questionnaire

for each hand was considered in the analysis ${ }^{24)}$. To qualitatively assess dietary habits, the food frequency questionnaire (FFQ) was used. The foods were grouped into milk and dairy products, meats and eggs, oils and fats, cereals, beans, vegetables, and fruits. Consumption frequency was expressed as daily, weekly, monthly, rarely, or never ${ }^{25}$.

Block 2: The following anthropometric variables were assessed according to the technical procedures described by the International Society for the Advancement of Kinanthropometry (ISAK): weight, height, triceps skinfold, subscapular skinfold, and circumference of the right arm, abdomen, waist, hip, and right calf ${ }^{25)}$. Complementing the assessment of body composition, a bioelectrical impedance analysis (BIA) was performed using a BIA $310 \mathrm{E}$ singlefrequency tetrapolar bioimpedance analyzer (Biodynamics, Seattle, WA, USA). The electrical current parameters were $800 \mathrm{~mA}$ and $50 \mathrm{KHz}$. Two electrodes were placed on the dorsum of the hand, and two electrodes were placed on the dorsum of the foot to determine total body bioimpedance. Participants were instructed regarding the preparations for the test $\mathrm{t}^{26)}$. The cutoff values for obesity were $35 \%$ for women and $25 \%$ for men ${ }^{27}$.

Two tests were used to evaluate body balance. The first was a static stabilometry test using an AccuSway Plus force platform (AMTI, Waltertown, MA, EUA). The center of foot pressure (COP) was captured with a frequency of $100 \mathrm{~Hz}$ and recorded using the Balance Clinic software (AMTI, Waltertown, MA, USA). The degree of oscillations in the standing position was assessed in the four positions described by Mainenti et al. ${ }^{8}$ : opened base with eyes open (OBEO), opened base with eyes closed (OBEC), closed base with eyes open (CBEO), and closed base with eyes closed (CBEC). The test duration was 60 seconds for each trial. The four positions were repeated, with a 1-minute interval between the tests. The order of the trials was randomized to minimize fatigue and learning effects. The following variables were calculated, as presented in the software's manual, using the COP signal: range and standard deviation of the COP, in both the anteroposterior and lateral directions, and the elliptical area. For each position, the smaller of the values from two trials was used for the analysis, since this 
value represents better postural control for the stabilometric variables analyzed.

Block 3: The second body balance assessment was the Berg scale, which evaluates the performance of static and dynamic functional balance through observation of 14 tasks and has a maximum score of 56 points. In this study, scores equal to or less than 45 points indicated a risk of falls, as described by Chiu et $\mathrm{al}^{28)}$. The degree of active movement of the right ankle was evaluated using a digital electrogoniometer. The electrogoniometer was fixed with tape on the lateral side of the ankle, its axis was positioned below the lateral malleolus toward the calcaneus, the fixed arm was placed parallel to the longitudinal axis of the tibia, and the movable arm was placed parallel to the lateral border of the foot, towards the 5th metatarsal. The subjects were asked to perform active flexion-extension movements of the right ankle joint while in the supine position. The examiner encouraged the participant to perform five repetitions of this movement at the maximum possible amplitude ${ }^{29}$. The measurements were collected via an electromyography channel (EMG-810; EMG System Do Brasil LTDA, São Paulo, Brazil), and the maximum amplitude was determined by Suíte MYO software ( $\mathrm{PhD}^{2}$ Consulting and System Ltda, Rio de Janeiro, Brazil). The six-minute walk test was performed to determine the submaximal physical capacity of the elderly. The subjects were instructed to walk down a corridor, as quickly as possible, for six minutes. Heart rate, oxygen saturation, and overall fatigue (Borg Scale) were evaluated at rest, then at the third minute of the test, and after the completion of the test. During the recovery period (one minute after finishing the test), these parameters were recorded again. The respiratory rate and blood pressure were measured at the beginning and end of the test. After the subject completed the test, the total distance walked over the six minutes was determined, and the percentage of the predicted walking distance was calculated as recommended by Dourado et al. ${ }^{30)}$, who performed a study with a Brazilian sample comprising subjects $60 \pm 9$ old. The sixminute walk test was performed twice, and the one with higher distance walked was used for the analysis. Finally, the perceived quality of life (QOL) was assessed using the WHOQOL-OLD, which has 24 items subdivided into the following six domains: sensory abilities, autonomy, past activities, present and future, social participation, death and dying, and intimacy. As recommended by the World Health Organization, the generic version of this instrument was applied. The WHOQOL-BREF evaluates two general questions about the quality of life, i.e., "How would you rate your quality of life?" and "How satisfied are you with your health?" in addition to 24 other questions related to the following four domains: "physical," "psychological," "social relationships," and "environment." The final scores from each instrument were calculated according the syntax proposed by the WHO, which considers the responses to each question and results in a final scores ranging from 0 (worst perceived QOL) to 100 (best perceived QOL).

For the data analysis, we used descriptive statistics, and the results were expressed as the mean \pm standard deviation, minimum and maximum values for numeric variables,
Table 1. General characteristics of the elderly who participated in the study $(\mathrm{n}=20)$

\begin{tabular}{lc}
\hline Variables & Frequency N (\%) \\
\hline Gender & \\
Female & $19(95 \%)$ \\
Male & $1(5 \%)$ \\
Marital Status & \\
Married & $0(0 \%)$ \\
Single & $2(10 \%)$ \\
Divorced & $2(10 \%)$ \\
Widowed & $16(80 \%)$ \\
Educational level & $1(5 \%)$ \\
Higher education & $8(40 \%)$ \\
Secondary education & $6(30 \%)$ \\
Complete primary & $5(25 \%)$ \\
Incomplete primary & \\
\hline
\end{tabular}

Values are expressed as absolute (n) and relative (\%) frequencies.

and absolute frequency (relative frequency) for categorical variables. Variable distributions were analyzed using the Kolmogorov-Smirnov test. To assess the correlation between variables, Pearson's correlation $(\rho)$ was used for parametric data, and the Spearman test was used for nonparametric data. To identify the strength of correlation between the variables analyzed, it was assumed that values from $0.0-0.29$ indicated weak correlation, values from $0.30-0.59$ indicated moderate correlation, values from $0.60-0.89$ indicated a strong correlation, and values from $0.90-1.00$ indicated very strong correlation ${ }^{31)}$.

Comparisons between groups (no risk of falls $v s$. risk of falls; obese $v s$. nonobese) were performed using the MannWhitney U test.

All statistical analyses were performed using the SPSS statistical software (SPSS Inc., Chicago, Illinois, USA, version 13.0), and a $p$ value of $\leq 0.05$ was considered statistically significant.

\section{RESULTS}

Fifty-one elderly were living in the LSI, but only 24 subjects agreed to voluntarily participate. Among these subjects, one was excluded because he could not walk by himself, and another three were excluded due to cognitive impairment. Twenty oldest old subjects participated in this study. They had a mean age of $85.8 \pm 5.2$ years. Most participants were female and widowed. The oldest participant in the institution had been residing there for 48 months (mean value: $19 \pm 15$ months), and most of the participants had completed secondary education. Furthermore, all reported right limb dominance (Table 1). Hemodynamic, anthropometric, body composition, and handgrip strength data are presented in Table 2. More than half of the participants $(60 \%)$ reported that they regularly engaged in some physical exercise, and of these, $33.3 \%$ reported engaging in activities once a week; $41.7 \%$ engaged in physical activities at least twice a week. The most commonly reported exercises 
1100 J. Phys. Ther. Sci. Vol. 26, No. 7, 2014

Table 2. Hemodynamic, anthropometric, body composition, and handgrip strength data for the elderly who participated in the study $(\mathrm{n}=20)$

\begin{tabular}{lccc}
\hline Variables & Mean \pm SD & Minimum & Maximum \\
\hline Systolic blood pressure at rest $(\mathrm{mmHg})$ & $134.3 \pm 17.7$ & 99.0 & 170.0 \\
Diastolic blood pressure at rest $(\mathrm{mmHg})$ & $76.9 \pm 13.1$ & 60.0 & 100.0 \\
Heart rate at rest $(\mathrm{bpm})$ & $74.1 \pm 16.5$ & 49.0 & 125.0 \\
Height $(\mathrm{m})$ & $1.51 \pm 0.06$ & 1.43 & 1.64 \\
Body weight $(\mathrm{kg})$ & $59.6 \pm 11.4$ & 44.7 & 82.5 \\
Body mass index $\left(\mathrm{kg} / \mathrm{m}^{2}\right)$ & $26.0 \pm 4.6$ & 19.1 & 34.8 \\
Arm circumference $(\mathrm{cm})$ & $29.8 \pm 4.2$ & 23.0 & 37.2 \\
Abdominal circumference $(\mathrm{cm})$ & $95.1 \pm 12.1$ & 60.5 & 111.9 \\
Waist circumference $(\mathrm{cm})$ & $89.4 \pm 10.5$ & 72.6 & 105.0 \\
Hip circumference $(\mathrm{cm})$ & $105.6 \pm 12.4$ & 92.0 & 128.0 \\
Calf circumference $(\mathrm{cm})$ & $31.9 \pm 3.1$ & 25.0 & 36.7 \\
Triceps skinfold $(\mathrm{mm})$ & $19.2 \pm 5.1$ & 10.2 & 28.5 \\
Subscapular skinfold $(\mathrm{mm})$ & $16.6 \pm 5.41$ & 8.5 & 29.2 \\
Waist to hip ratio & $0.84 \pm 0.06$ & 0.76 & 0.94 \\
Fat-free mass $(\mathrm{kg})$ & $36.4 \pm 6.0$ & 27.1 & 47.5 \\
Fat mass $(\mathrm{kg})$ & $23.8 \pm 7.1$ & 13.0 & 40.6 \\
Fat mass percentage $(\%)$ & $39.0 \pm 5.5$ & 29.0 & 48.0 \\
Right handgrip strength $(\mathrm{kg})$ & $16.40 \pm 6.8$ & 8.0 & 27.0 \\
Left handgrip strength $(\mathrm{kg})$ & $14.60 \pm 6.2$ & 6.0 & 27.0 \\
\hline
\end{tabular}

were yoga (50\%), dance (25\%), and gymnastics $(17 \%)$.

The participants' scores on the Berg Balance Scale ranged between 10 and 56, with a mean of $45.9 \pm 11.5$. By analyzing these values with respect to handgrip, we observed a strong positive correlation for right handedness ( $r$ $=0.62$ ) and a moderate positive correlation for left handedness $(r=0.57)$, both of which were statistically significant. Another positive and significant correlation was found between the Berg Balance Scale score and the distance walked during the six-minute walk test, as well as the percentage of predicted walking $(r=0.56 ; r=0.57$, respectively). The Berg Balance Scale correlations with the stabilometric variables were negative, especially when considering the range and standard deviation of the center of pressure of the foot while performing the test in closed base conditions, both in the anteroposterior and lateral directions (Table 3). Using a cutoff of 45 points $^{28)}$ on the Berg Balance Scale, it was observed that $40 \%(n=8)$ of the participants were at risk of falls, and these subjects had lower manual strength and walked a shorter distance during the six-minute walk test; they also had lower percentages of predicted distance values compared with those who were not at risk of falls (Table 4).

The degree of mobility of the right ankle showed a significant positive correlation $(\mathrm{r}=0.47)$ with the distance walked during the six-minute walk test.

Table 5 shows the cardiorespiratory control results from the six-minute walk test. Two participants regretted performing this test because they had been unwilling to perform the test before enrollment. The mean distance walked during the test was $181.1 \pm 91.6$ meters, which corresponds to $36.8 \pm 17.9 \%$ of the predicted values according to the formula proposed by Dourado et $\mathrm{al}^{30)}$.
Table 3. Correlations between Berg Balance Scale scores and the six-minute walk test, handgrip strength, and stabilometric variables $(\mathrm{n}=20)$

\begin{tabular}{|c|c|}
\hline Variables & $\mathrm{r}$ \\
\hline $\mathrm{WT}_{6 \min }$ & $0.56^{*}$ \\
\hline$\%$ of $\mathrm{WT}_{6 \min }$ predicted distance $\mathrm{e}^{30}$ & $0.57^{*}$ \\
\hline RHS & $0.62 *$ \\
\hline LHS & $0.57 *$ \\
\hline CBEO - Lateral standard deviation & $-0.55^{*}$ \\
\hline CBEO - AP standard deviation & $-0.61^{*}$ \\
\hline $\mathrm{CBEO}-\mathrm{AP}$ range & $-0.62 *$ \\
\hline CBEO - Area & $-0.61^{*}$ \\
\hline CBEC - Lateral standard deviation & $-0.62 *$ \\
\hline CBEC - AP standard deviation & $-0.59 *$ \\
\hline CBEC - Lateral range & $-0.62 *$ \\
\hline $\mathrm{CBEC}-\mathrm{AP}$ range & $-0.52 *$ \\
\hline $\mathrm{CBEC}-$ Area & $-0.69 *$ \\
\hline
\end{tabular}

${ }^{*} \mathrm{p}<0.05$. r, Pearson's correlation coefficient; $\mathrm{WT}_{6 \text { min }}$, distance covered in the six-minute walk test; RHS, right handgrip strength; LHS, left handgrip strength; CBEO, closed base with eyes open; CBEC, closed base with eyes closed; AP, anteroposterior direction of center of pressure oscillation

The body composition by bioelectrical impedance analysis indicated that 15 subjects were obese ${ }^{27)}$ and their obesity was associated with worse stabilometric variables for the OBEO position (Table 6). By analyzing waist circumference, we identified that $78.9 \%$ of the subjects had central fat accumulation using cutoff values of $>88 \mathrm{~cm}$ for women and $>102 \mathrm{~cm}$ for $\mathrm{men}^{32)}$. 
Table 4. Handgrip strength and walking test values for the group with no risk of falls and the group with risk of falls

\begin{tabular}{lcc}
\hline \multirow{2}{*}{ Variables } & No risk of falls & Risk of falls \\
& $\mathrm{n}=12$ & $\mathrm{n}=8$ \\
\hline RHS $(\mathrm{kgf})$ & $20.3 \pm 5.9$ & $10.6 \pm 2.6^{*}$ \\
LHS $(\mathrm{kgf})$ & $17.8 \pm 5.7$ & $9.9 \pm 3.1^{*}$ \\
$\mathrm{WT}_{6 \text { min }}(\mathrm{m})$ & $218.6 \pm 94.5$ & $134.1 \pm 66.4^{*}$ \\
$\%$ of $\mathrm{WT}_{6 \text { min }}$ predicted distance $^{30)}(\%)$ & $43.8 \pm 17.8$ & $28.0 \pm 14.5$ \\
\hline
\end{tabular}

*Mann-Whitney U Test - statistically significant at $\mathrm{p}<0.05$. RHS, right handgrip strength;

LHS, left handgrip strength; $\mathrm{WT}_{6 \mathrm{~min}}$, distance walked in the six-minute walk test

Table 5. Cardiorespiratory control variables during the six-minute walk test $(\mathrm{n}=18)$

\begin{tabular}{lcccccc}
\hline Variables & Pretest & $3^{\circ}$ min TC6 & End TC6 & Rec $1^{\circ} \min$ & $\Delta$ Borg & $\Delta$ Rec \\
\hline $\mathrm{HR}(\mathrm{bpm})$ & $74.6 \pm 16.0$ & $97.5 \pm 17.5$ & $95.2 \pm 19.0$ & $84.4 \pm 16.7$ & $20.6 \pm 11.3$ & $10.7 \pm 5.6$ \\
$\mathrm{SatO}_{2}(\%)$ & $94.9 \pm 3.9$ & $94.1 \pm 3.1$ & $94.1 \pm 3.8$ & $95 \pm 4.9$ & $-0.9 \pm 5.8$ & $-0.9 \pm 3.4$ \\
Borg scale & $0 \pm 1$ & $2 \pm 2$ & $4 \pm 3$ & $3 \pm 3$ & $4 \pm 3$ & $1 \pm 1$ \\
$\mathrm{RR}(\mathrm{ipm})$ & $20.5 \pm 6.6$ & - & $23.8 \pm 6.5$ & - & $3.3 \pm 1.9$ & - \\
$\mathrm{SBP}(\mathrm{mmHg})$ & $128.9 \pm 19.7$ & - & $136.1 \pm 17.2$ & - & $7.2 \pm 11.3$ & - \\
$\mathrm{DBP}(\mathrm{mmHg})$ & $72.8 \pm 9.6$ & - & $78.3 \pm 10.4$ & - & $5.6 \pm 8.6$ & - \\
\hline
\end{tabular}

Rec 1 min, measurement taken one minute after the end of the test; $\Delta$ Borg calculated as end - Pretest; $\Delta$ Rec calculated as End - Rec $1 \mathrm{~min}$; HR, heart rate; $\mathrm{SpO}_{2}$, oxygen saturation; RR, respiratory rate; SBP, systolic blood pressure; DBP, diastolic blood pressure; $\mathrm{WT}_{6}$, six-minute walk test

Table 6. Stabilometric variables for the obese and nonobese groups

\begin{tabular}{lcc}
\hline Variables & $\begin{array}{c}\text { Obese } \\
\mathrm{n}=15\end{array}$ & $\begin{array}{c}\text { Nonobese } \\
\mathrm{n}=4\end{array}$ \\
\hline BOEO - End.SDx $(\mathrm{cm})$ & $0.34 \pm 0.44$ & $0.13 \pm 0.38^{*}$ \\
BOEO - End.RANGEx $(\mathrm{cm})$ & $2.28 \pm 3.41$ & $0.84 \pm 0.13^{*}$ \\
BOEO - End.Area $\left(\mathrm{cm}^{2}\right)$ & $3.41 \pm 7.63$ & $0.60 \pm 2.61^{*}$ \\
\hline *Mann-Whitney U Test - statistically significant at $\mathrm{p}<0.05$. BOEO: Base open \\
with eyes closed
\end{tabular}

Table 7. Quality of life scores according to WHOQOL-BREF and WHOQOL-OLD instruments $(\mathrm{n}=20)$

\begin{tabular}{lccc}
\hline WHOQOL-BREF Domains & Median & Minimum & Maximum \\
\hline Physical & 62.9 & 22.9 & 94.3 \\
Psychological & 68.3 & 26.7 & 93.3 \\
Social relations & 60.0 & 20.0 & 100.0 \\
Environment & 71.3 & 27.5 & 95.0 \\
Total & 63.9 & 24.3 & 93.3 \\
WHOQOL-OLD Facets & & & \\
Sensorimotor functioning & 70.0 & 20.0 & 100.0 \\
Autonomy & 60.0 & 20.0 & 90.0 \\
Past, present, and future activities & 70.0 & 25.0 & 95.0 \\
Social participation & 65.0 & 35.0 & 100.0 \\
Death and dying & 77.5 & 20.0 & 100.0 \\
Intimacy & 70.0 & 20.0 & 100.0 \\
Total & 64.6 & 45.0 & 90.0 \\
\hline
\end{tabular}

Regarding the overall perception of quality of life, $10 \%$ of the oldest old rated their quality of life as very good, $40 \%$ rated it as good, and another $40 \%$ rated it as neither good nor bad. In terms of their satisfaction with their own health, we found that $50 \%$ of the elderly were satisfied, $20 \%$ were neither satisfied nor dissatisfied, and $15 \%$ were very 


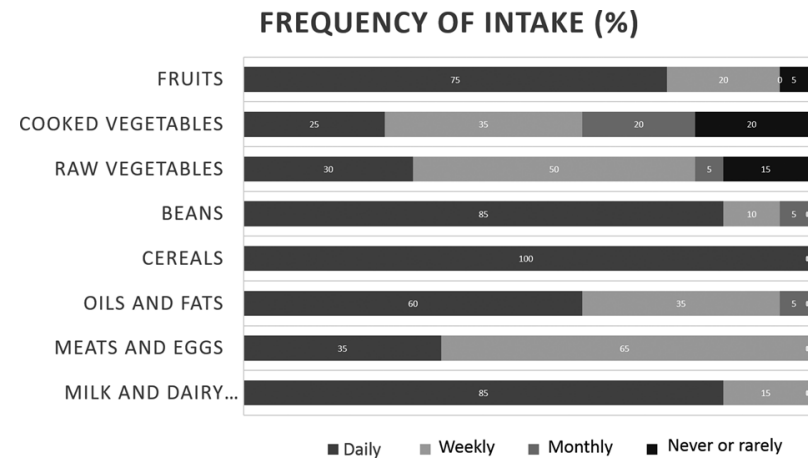

Fig. 2. Frequency of intake among the elderly in the long-stay institution

dissatisfied. All of the perceived quality of life results are presented in Table 7.

The results of the food frequency questionnaire (FFQ) were as follows: regarding protein-rich food, $85 \%$ of the elderly consumed milk or milk derivatives daily, and $15 \%$ consumed milk weekly (Fig. 2). Thirty-five percent of the participants reported daily meat and egg consumption, and $65 \%$ reported weekly consumption. By contrast, beans were consumed daily by $85 \%$ of the participants, weekly by $10 \%$ of the participants, and monthly by $5 \%$ of the participants.

\section{DISCUSSION}

The oldest old participants of this study were predominantly female, widowed, and obese and had perceived quality of life scores equal or higher than $60 \%$ for all domains. Forty percent of the assessed elderly were at risk of falls, as measured by the Berg Balance Scale. The risk of falls group presented a low handgrip strength and short distance walked in the six-minute walk test. Seventy-five percent of the sample was obese. The obese group presented worse postural control (higher stabilometric variables) compared with the nonobese group. The Berg Balance Scale scores were positively correlated with the handgrip strength and the distance walked in the six-minute walk test. Furthermore, the mobility of the ankle joint presented also positive and significant correlation with the distance walked in the six-minute walk test. Finally, some stabilometric variables presented negative correlations with Berg Balance Scale scores.

This study was carried out in a long-stay institution in the city of Rio de Janeiro, Brazil. It is a private institution that welcomes elderly individuals over 60 years of age, who stay in single rooms and have access to television, magazines, and newspapers. The institution offers its guests leisure and health activities, such as dance, yoga, painting, embroidery, physiotherapy, and medical monitoring. Because the elderly residents have no major clinical impairments, they had the freedom to leave the institution to go on tours and sightseeing and shopping excursions.

The subjects belonged to the age group known as "the very very old" or "the oldest old". Baltes and Smith ${ }^{33)}$ reported that this group of seniors has distinct characteris- tics because disabling events become increasingly common over the years. This perspective leads us to believe that living longer results in greater need for care and consequently greater demand for the use of long-stay institutions. Most participants in this study were female, reflecting the greater longevity of women compared with men, as already report$\mathrm{ed}^{34-37)}$ and which is attributed to environmental, social, and genetic factors.

With regard to the distribution of fat, it is known that the apex of fat accumulation occurs at approximately 45-49 years in men and between $60-70$ years in women ${ }^{10)}$, which may explain the results of our BIA and waist circumference analysis. These findings are corroborated by other studies demonstrating the prevalence of obesity in the elder$1 y^{32,38-43)}$. However, Moreira et al. ${ }^{44)}$ reported that in their study, the nutritional status of the elderly was eutrophic. This classification was assigned because the authors used BMI as a single classifier of nutritional status. The applicability of BMI in the elderly has been questioned, as it does not account for the distribution of body fat (BF). Knowing that the elderly experience bodily changes relative to the location of fat distribution, amount of body water, muscle loss, and decrease in height, among alterations, it is possible that two people with the same BMI may have different percentages of BF. Moreover, it is observed that in the elderly, gradual loss of muscle mass can be masked by fat gain. This relationship is called sarcopenic obesity, which is often associated with normal BMI but increased waist circumference $^{45}$. Other studies ${ }^{10,46)}$ reporting on the body composition of very elderly seniors highlighted the decline in body fat concentration in this age group. However, due to the cross-sectional nature of our study, it is difficult to determine whether the very elderly in our study experienced a gradually declining concentration of BF. Determining the nutritional status of the very elderly is not an easy task because there are several indicators (dietary, anthropometric, and biochemical) and influencing factors (gender, age, race, physical activity level, health status) ${ }^{10)}$.

Changes in body composition usually follow a programmed genetic pattern and are caused by changes in diet, physical activity level, and the association between these factors; when the elderly are institutionalized, these influences are even more significant. Therefore, anthropometric analysis should always be addressed in discussions about the aging process because such changes are directly related to the onset of comorbidities and mortality ${ }^{44)}$. With aging, a gradual decline in physical activity and a consequent increase in sedentary behavior ${ }^{47,48)}$ are additional factors that influence the change in body composition. A sedentary lifestyle also affects functional variables such as postural balance, cardiovascular endurance, flexibility, and muscle strength.

A threshold force to maintain postural balance is required to perform every task, and it is likely that greater muscle strength provides better stability and alignment control. Thus, any reduction in muscle strength or balance adversely influences the performance of activities of daily living ${ }^{49,50)}$. Handgrip strength has been shown to be predictive of overall muscular strength ${ }^{23)}$, nutritional status ${ }^{51)}$, and 
functional performance in the elderly ${ }^{52,53)}$. In this study, it was observed that the higher the handgrip strength, the higher the values achieved in the Berg test. This finding is corroborated by those of Rebellato et al. ${ }^{54)}$, who found that a group of seniors who reported having suffered declines over the past year had lower muscle strength than seniors who reported no falls.

Rantanen et al. ${ }^{55)}$ followed a cohort 919 elderly American women and showed that the handgrip strength test can also be used as a predictor of mortality and may thus be helpful in identifying patients who are at an increased risk of health deterioration. Ribeiro and Pereira ${ }^{56}$ found that the Berg Balance Scale is the most accurate scale for detecting changes in balance in the elderly. In our study, we found Berg balance scale scores under 45 points in $40 \%$ of the participants. This finding is similar to that reported by Pimentel and Scheicher ${ }^{57)}$, who investigated the risk of falls in 70 sedentary and active elderly subjects using the Berg balance scale and found that the risk of falls was $40 \%$ in the active group and $97.14 \%$ in the sedentary group. There were significant negative correlations between Berg balance scale scores and stabilometric variables, showing that those participants with high functional balance presents small body sway during static posture. This was an expected result, considering that a smaller center of pressure movement in a task denotes better postural control.

In the present study, we observed that the group with no risk of falling walked a longer distance compared with the group that had an increased risk of falling. It is noteworthy that all participants in the group that had an increased risk of falls needed help walking while performing any test and that two participants in this group failed to repeat the test. It is recommended that the six-minute walk test be performed twice, with a 15-minute interval between trials, to overcome the learning curve and to ensure reproducibility of the procedure. However, our data suggest that in regard to very elderly seniors, this recommendation should be reconsidered because we observed that repetition required too much effort, and thus, some of the elderly people refused to repeat the test and others exhibited worse performance.

Another correlation found in this study was between the mobility of the right ankle and the distance walked during the six-minute walk test, most likely because with aging, changes occur in the mechanical and morphological properties of the structures that cause myoarticular tendon stiffness, changes in the joint capsules, stiffness in muscles, and decreases in synovial fluid ${ }^{58)}$. Another factor that may have contributed to this correlation is the fact that ankle mobility is also related to functional balance in the elderly ${ }^{59)}$. The walk test is widely used to evaluate the physical ability of the elderly to predict morbidity and mortality, follow the evolution of diseases, assist in creating a functional profile of different population groups, generate evaluative parameters before and after therapeutic interventions, and develop recommendations for safe and effective exercises ${ }^{60)}$.

Dietary intake is another central factor for quality of life in the elderly ${ }^{61)}$. The diet may contribute to reductions in various worsening health factors. However, with economic development, especially in Western countries, changes can be observed in the food consumption of the population, with increasing use of industrialized foods that have a high caloric density and very high concentration of saturated fat and sodium. In addition, there is a decreased need for energy expenditure while performing activities of daily living and working, resulting in an increase in health problems such as obesity, diabetes mellitus, hypertension, and some types of cancer ${ }^{61)}$.

The information obtained from the analysis of dietary intake data was related to the food guide recommendations for the Brazilian population ${ }^{62)}$. Najas et al. ${ }^{63)}$ studied the eating patterns of elderly individuals from different socioeconomic strata living in urban regions in southeastern Brazil. The authors found that more than $70 \%$ of the elderly population consumed beans, beef, poultry, milk, dairy products, and eggs. Analysis of the relative frequencies of daily consumption demonstrated that the most frequently consumed protein-rich foods were beans, milk, and milk derivatives, as observed in our study.

With respect to foods with high nutritive value (carbohydrates and fats), it was observed that $100 \%$ of the study population consumed cereal daily. This finding is in accordance with that of Najas et al. ${ }^{63)}$, who found that more than $90 \%$ of the elderly consume rice, bread, starchy foods, and pasta, and the items most commonly consumed daily ( $>70 \%)$ were rice and bread. Analysis of the consumption of fats in the form of oils, margarine, and butter showed that $60 \%$ of elderly individuals consume fats daily, $35 \%$ consume them weekly, and 5\% consume them monthly.

Shin-Jiuan et al. ${ }^{64)}$ examined the dietary intake levels and major food sources of energy and nutrients among the Taiwanese elderly and observed that meat and cereals/roots were the major sources of dietary protein. Whereas cereals/ roots were the main carbohydrate-contributing food group, the primary lipid sources were meat and fats/oils among the elderly.

In assessing the consumption of fruits and vegetables, which represent sources of micronutrients (vitamins and minerals), it was revealed that $75 \%$ of the elderly consumed fruits daily but that the consumption of raw or cooked vegetables was low, at $30 \%$ and $25 \%$ daily, respectively. It is worth noting that the frequency of "never or rarely" consuming these foods was $5 \%$ for fruits, $20 \%$ for cooked vegetables, and $15 \%$ for raw vegetables. Shin-Jiuan et al. ${ }^{64)}$ also verified that the highest ranked dietary sources for minerals for the Taiwanese elderly were as follows: dairy products, vegetables, and seafood for calcium; dairy products and cereals/roots for phosphorous; vegetables and meat for iron; and vegetables, cereals/ roots, other protein-rich foods, and seafood for magnesium.

Viebig et al. ${ }^{65)}$, in a study involving 2,066 low-income elderly individuals ( $\geq 60$ years) living in the city of São Paulo, reported that approximately one-third of their subjects $(\mathrm{n}=$ $723 ; 35 \%$ ) did not consume any type of fruit or vegetable on a daily basis. In addition, $19.8 \%$ reported a daily intake of five or more servings of fruits and vegetables. This intake was positively associated with income and years of schooling. Jaime et al. ${ }^{66)}$ estimated that the consumption of fruits and vegetables in Brazil is less than half of the recommended amount, especially in low-income families.

Regarding the quality of life test, it was observed that 
all domains assessed by the WHOQOL-BREF, except for social relations, had scores above $60 \%$ and that all facets analyzed by the WHOQOL-OLD also showed scores above $60 \%$. One of the biggest reasons why families choose institutionalization is that they are concerned about their elderly relative living alone due to fears regarding social isolation and the difficulty of maintaining independence ${ }^{67)}$. It is believed that in a long stay institution, the elderly share fellowship with their peers, which helps reduce loneliness. However, a study by Prieto-Flores et al. ${ }^{68)}$ shows that institutionalization alone has a strong effect on loneliness that is not ameliorated by the possibility of meeting with family, friends, and neighbors. Therefore, it is believed that feeling isolated from family and friends were the main reason why the participants in this study had low scores in the social relations domain of the WHOQOL-OLD. The effects of social relationships on quality of life in the elderly are so important that, after completing a longitudinal study on British elderly subjects and studying the influence of age on quality of life, Zaninotto et al. ${ }^{69)}$ proposed that it is necessary to prepare adults at a younger age through strategies that may increase their network of friends and interaction with a wider community.

The scores for the facet related to death and dying were higher, which leads us to believe that elderly individuals understand that aging and death are a natural process of human existence. Such acceptance may also be compounded by the fact that the elderly have already mourned the death of their companions, relatives, and friends. Frumi and Celich $^{70)}$ reported that appreciation and respect for older people's life histories leads to recognition of an individual's uniqueness and the importance of promoting healthy aging.

Despite the fact that it studied such an important group in the Brazilian population, this study has some limitations. Body fat was measured by the bioelectrical impedance technique and not by dual energy X-ray absorptiometry (DXA), one of the gold standard exams for body composition evaluation. Furthermore, physical capacity was not measured by a cardiopulmonary exercise test (ergospirometry), a gold standard for physical capacity evaluation, but was measured by an indirect method, the six-minute walk test. It is desirable, mainly in scientific literature, to use the most reliable methods. The methods applied in the present study, nevertheless, are frequently used in clinics and were feasible, since all measurements were performed in the LSI.

In conclusion, the oldest old participants in this study were predominantly female, widowed, and obese. Of all subjects evaluated, $40 \%$ had a risk of falls, and these individuals had the worst results for handgrip strength and the walking test. The high values for obesity and low values for handgrip strength and physical capacity were associated with worse body balance. Furthermore, the low values for ankle joint mobility were also associated with worse physical capacity in this population. In the perceived quality of life assessment, the social relations domain had the worst scores, and the death and dying domain had the best scores.

These individuals are therefore a very vulnerable age group, and relevant risk prevention strategies should include social interaction as a facilitator in programs aimed at preventing functional disability. Studies related to the oldest old, particularly those in long-stay institutions, are scarce. Therefore, we suggest that future research should include larger groups, as well as individuals residing in public institutions, and should focus on assessing therapeutic proposals, which may inform the development of public policies more targeted and appropriate for this population.

\section{ACKNOWLEDGEMENT}

This study was partially supported by Fundação Carlos Chagas Filho de Amparo à Pesquisa do Estado do Rio de Janeiro (FAPERJ).

\section{REFERENCES}

1) IBGE: Senso demográfico 2010. Sinopse do senso demográfico 2010. População residente, por sexo e grupos de idade. http://www.censo2010.ibge. gov.br/sinopse/index.php?dados $=12 \& u f=00 \#$ topo_piramide (Accessed May 9, 2012)

2) BRASIL: Ministério da Saúde. Diretrizes operacionais: Pactos pela vida, em defesa do SUS e de gestão. Brasília: Secretaria Executiva, Departamento de Apoio à Descentralização, 2006. http://dtr2001.saude.gov.br/ editora/produtos/livros/pdf/06 0257 M.pdf (Accessed Apr. 7, 2013)

3) Matsudo SM, Matsudo VK, de Barros Neto TL: Atividade física e envelhecimento: aspectos epidemiológicos. Rev Bras Med Esporte, 2001, 7: 2-13.

4) Navarro FM, Rabelo JF, Faria ST, et al.: [Perceptions of a group of elderly people regarding the influence of physical activity on their lives]. Rev Gaucha Enferm, 2008, 29: 596-603. [Medline]

5) Jeon BJ, Cha TH: The effects of balance of low vision patients on activities of daily living. J Phys Ther Sci, 2013, 25: 693-696. [Medline] [CrossRef]

6) Regolin F, Carvalho GA: Relationship between thoracic kyphosis, bone mineral density, and postural control in elderly women. Rev Bras Fisioter, 2010, 14: 464-469. [Medline]

7) Gomez-Cabello A, Pedrero-Chamizo R, Olivares PR, et al. EXERNET Study Group: Prevalence of overweight and obesity in non-institutionalized people aged 65 or over from Spain: the elderly EXERNET multicentre study. Obes Rev, 2011, 12: 583-592. [Medline] [CrossRef]

8) Mainenti MR, Rodrigues EC, Oliveira JF, et al.: Adiposity and postural balance control: correlations between bioelectrical impedance and stabilometric signals in elderly Brazilian women. Clinics (Sao Paulo), 2011, 66 : 1513-1518. [Medline]

9) Rebelatto JR, Calvo JI, Orejuela JR, et al.: Influence of a long-term physical activity program on hand muscle strength and body flexibility among elderly women. Rev Bras Fisioter, 2006, 10: 127-132. [CrossRef]

10) Matsudo SM, Matsudo VK, de Barros Neto TL: The impacto for aging on anthropometric, neuromotor, and metabolic variables of physical fitness. Rev Bras Cien Mov, 2000, 8: 21-32.

11) Lanza IR, Russ DW, Kent-Braun JA: Age-related enhancement of fatigue resistance is evident in men during both isometric and dynamic tasks. J Appl Physiol 1985, 2004, 97: 967-975. [Medline] [CrossRef]

12) Matsudo SM, Matsudo VK, de Barros Neto TL: Heart rate, arterial blood pressure and double products during resistance dynamic and aerobic exercices. Rev Bras Ativ Fis Saude, 2000, 5: 60-76.

13) Cheik NC, Reis IT, Heredia RA, et al.: Effects of the physical exercise and physial activity on the depression and anxiety in elderly. R Bras Ci Mov, 2003, 11: 45-52.

14) Lee D, Ko T, Han S: Effects of Community-Dwelling Older Adults' Demographics and Social, Mental, and Physical Functions on Depressive Disorder. J Phys Ther Sci, 2013, 25: 463-466. [CrossRef]

15) Gomes GA, Cintra FA, Batista FS, et al.: Elderly outpatient profile and predictors of falls. Sao Paulo Med J, 2013, 131: 13-18. [Medline]

16) Fabrício SC, Rodrigues RA, da Costa ML Jr: [Falls among older adults seen at a São Paulo State public hospital: causes and consequences]. Rev Saude Publica, 2004, 38: 93-99. [Medline]

17) Veras RP: International experiences and trends in health care models for the elderly. Ciênc saúde coletiva, 2012, 17: 231-238.

18) de Oliveira MP, Novaes MR: [The socio-economic, epidemiological and pharmaco-therapeutic profile of institutionalized elderly individuals in Brasilia, Brazil]. Cien Saude Colet, 2013, 18: 1069-1078. [Medline]

19) Rodrigues AG, da Silva AA: The social network and types of support received by the institutionalized elderly. Rev Bras Geriatr Gerontol, 2013, 16: 159-170. [CrossRef] 
20) Creutzberg M, Gonçalves LH, Sobottka EA: Long time institutions for the elderly: the image that stays. Texto Contexto-enferm, 2008, 17: 273-279.

21) Telarolli Júnior R, Machado JC, Carvalho F: [Demographic profile an health conditions of the elderly in a community in an urban area of southeastern Brazil]. Rev Saude Publica, 1996, 30: 485-498. [Medline]

22) Brucki SM, Nitrini R, Caramelli P, et al.: [Suggestions for utilization of the mini-mental state examination in Brazil]. Arq Neuropsiquiatr, 2003, 61 777-781. [Medline] [CrossRef]

23) Desrosiers J, Bravo G, Hébert R, et al.: Normative data for grip strength of elderly men and women. Am J Occup Ther, 1995, 49: 637-644. [Medline] [CrossRef]

24) Moreira D, Álvarez RR, de Gogoy JR, et al.: Aproach about palmar prehension using dynamometer $\mathrm{JAMAR}^{\circledR}$ : a literature revision. R Bras $\mathrm{C}$ Mov, 2003, 11: 95-99.

25) Ribeiro AC, Sávio KE, Rodrigues ML, et al.: Validation of a food frequency questionnaire for the adult population. Rev Nutr Campinas, 2006 19: 553-562. [CrossRef]

26) Rech CR, Cordeiro BA, Petroski EL, et al.: Validation of bioelectrical impedance for the prediction of fat-free mass in Brazilian elderly subjects Arq Bras Endocrinol Metabol, 2008, 52: 1163-1171. [Medline] [CrossRef]

27) Deurenberg P, Andreoli A, Borg P, et al.: The validity of predicted body fat percentage from body mass index and from impedance in samples of five European populations. Eur J Clin Nutr, 2001, 55: 973-979. [Medline] [CrossRef]

28) Chiu AY, Au-Yeung SS, Lo SK: A comparison of four functional tests in discriminating fallers from non-fallers in older people. Disabil Rehabil, 2003, 25: 45-50. [Medline] [CrossRef]

29) Nolasco C de S, Reis FA dos, Figueiredo AM de, et al.: Reliability and applicability of two methods for evaluating the range of motion for ankle dorsiflexion. ConScientiae Saude, 2011, 10: 83-92. [CrossRef]

30) Dourado VZ, Vidotto MC, Guerra RL: Reference equations for the performance of healthy adults on field walking tests. J Bras Pneumol, 2011, 37 607-614. [Medline] [CrossRef]

31) Callegari-Jacques SM: Bioestatística: princípios e aplicações. Porto Alegre: Artemed, 2003.

32) Kumpel DA, Sodré A de C, Pomatti DM, et al.: Obesity among elderly accompanied by the brazilian family health strategy. Texto contexto - enferm, 2011, 20: 271-277.

33) Baltes PB, Smith J: New frontiers in the future of aging: from successful aging of the young old to the dilemmas of the fourth age. Gerontology, 2003, 49: 123-135. [Medline] [CrossRef]

34) Franceschi C, Motta L, Valensin S, et al.: Do men and women follow different trajectories to reach extreme longevity? Italian Multicenter Study on Centenarians (IMUSCE). Aging (Milano), 2000, 12: 77-84. [Medline]

35) Tigani X, Artemiadis AK, Alexopoulos EC, et al.: Gender differences in Greek centenarians. A cross-sectional nation-wide study, examining multiple socio-demographic and personality factors and health locus of control. BMC Geriatr, 2011, 11: 87. [Medline] [CrossRef]

36) Maués CR, Paschoal SM, Jaluul O, et al.: Assessment of quality of life: comparison between elderly young and very old. Rev Bras Clin Med, 2010 8: 405-410.

37) Coelho Filho JM, Ramos LR: [Epidemiology of ageing in Northeastern Brazil: results of a household survey]. Rev Saude Publica, 1999, 33: 445453. [Medline] [CrossRef]

38) Sánchez-García $S$, García-Peña C, Duque-López MX, et al.: Anthropometric measures and nutritional status in a healthy elderly population. BMC Public Health, 2007, 7: 2. [Medline] [CrossRef]

39) Arterburn DE, Crane PK, Sullivan SD: The coming epidemic of obesity in elderly Americans. J Am Geriatr Soc, 2004, 52: 1907-1912. [Medline] [CrossRef]

40) Mathus-Vliegen EM, Basdevant A, Finer N, et al. Obesity Management Task Force of the European Association for the Study of Obesity: Prevalence, pathophysiology, health consequences and treatment options of obesity in the elderly: a guideline. Obes Facts, 2012, 5: 460-483. [Medline] [CrossRef]

41) Bakhshi E, Seifi B, Biglarian A, et al.: Factors associated with obesity in Iranian elderly people: results from the national health survey. BMC Res Notes, 2011, 4: 538. [Medline] [CrossRef]

42) dos Santos DM, Sichieri R: [Body mass index and measures of adiposity among elderly adults]. Rev Saude Publica, 2005, 39: 163-168. [Medline]

43) Bueno JM, Martino HS, Fernandes MF, et al.: [Nutritional evaluation and prevalence of not transmissible chronic disease in elderly participating in an assistance program]. Cien Saude Colet, 2008, 13: 1237-1246. [Medline] [CrossRef]

44) Moreira AJ, Nicastro H, Cordeiro RC, et al.: Body composition of elderly by anthropometry. Rev Bras Geriatr Gerontol, 2009, 12: 201-213.
45) Waters DL, Baumgartner RN: Sarcopenia and obesity. Clin Geriatr Med, 2011, 27: 401-421. [Medline] [CrossRef]

46) de Menezes TN, de Fátima Nunes Marucci M: [Anthropometry of elderly people living in geriatric institutions, Brazil]. Rev Saude Publica, 2005, 39: 169-175. [Medline]

47) Dias-da-Costa JS, Hallal PC, Wells JC, et al.: Epidemiology of leisure-time physical activity: a population-based study in southern Brazil. Cad Saude Publica, 2005, 21: 275-282. [Medline] [CrossRef]

48) Hallal PC, Dumith SC, Bastos JP, et al.: [Evolution of the epidemiological research on physical activity in Brazil: a systematic review]. Rev Saude Publica, 2007, 41: 453-460. [Medline] [CrossRef]

49) Tavares AC, Sacchelli T: Functional activity evaluation in elderly people after cinesiotherapy. Rev Neurociencia, 2009, 17: 19-23.

50) Brawley LR, Rejeski WJ, King AC: Promoting physical activity for older adults: the challenges for changing behavior. Am J Prev Med, 2003, 25: 172-183. [Medline] [CrossRef]

51) Norman K, Stobäus N, Gonzalez MC, et al.: Hand grip strength: outcome predictor and marker of nutritional status. Clin Nutr, 2011, 30: 135-142. [Medline] [CrossRef]

52) Geraldes A, de Oliveira AR, de Albuquerque RB: The hand-grip forecasts the functional performance of fragile elder subjects: a multiple-correlation study. Rev Bras Med Esporte, 2008, 14: 12-16. [CrossRef]

53) Stevens PJ, Syddall HE, Patel HP, et al.: Is grip strength a good marker of physical performance among community-dwelling older people? J Nutr Health Aging, 2012, 16: 769-774. [Medline] [CrossRef]

54) Rebelatto JR, de Castro AP, Chan A: Falls in institutionalized elderly people: general characteristics, determinant factors and relationship with handgrip strength. Acta Ortop Bras, 2007, 15: 151-154.

55) Rantanen T, Volpato S, Ferrucci L, et al.: Handgrip strength and causespecific and total mortality in older disabled women: exploring the mechanism. J Am Geriatr Soc, 2003, 51: 636-641. [Medline] [CrossRef]

56) Ribeiro AS, Pereira JS: Balance improvement and reduction of likelihood of falls in older women after Cawthorne and Cooksey exercises. Braz J Otorhinolaryngol, 2005, 71: 38-46. [Medline]

57) Pimentel RM, Scheicher ME: Comparison of fall risk between sedentary and active aged by means of the Berg balance scale. Fisioter Pesqui, 2009, 16: 6-10

58) Mecagni C, Smith JP, Roberts KE, et al.: Balance and ankle range of motion in community-dwelling women aged 64 to 87 years: a correlational study. Phys Ther, 2000, 80: 1004-1011. [Medline]

59) Cho B, Ko T, Lee D: Effect of ankle joint mobilization on range of motion and functional balance of elderly adults. J Phys Ther Sci, 2012, 24: 331-333. [CrossRef]

60) ATS Committee on Proficiency Standards for Clinical Pulmonary Function Laboratories: ATS statement: guidelines for the six-minute walk test. Am J Respir Crit Care Med, 2002, 166: 111-117. [Medline] [CrossRef]

61) Abreu ES de, Viana IC, Moreno RB, et al.: Alimentação mundial: uma reflexão sobre a história. Saúde soc., 2001, 10: 3-14.

62) Carlos JV, Rolim S, Bueno MB, et al: Portion sizes of the main foods and preparations consumed by adults and elderly living in the city of São Paulo, Brazil Rev Nutr, 2008, 21: 383-391. [CrossRef]

63) Najas MS, Andreazza R, de Souza AL, et al.: [Eating patterns among the elderly of different socioeconomic groups living in a urban area of southeastern Brazil]. Rev Saude Publica, 1994, 28: 187-191. [Medline] [CrossRef]

64) Wu SJ, Chang YH, Wei IL, et al.: Intake levels and major food sources of energy and nutrients in the Taiwanese elderly. Asia Pac J Clin Nutr, 2005, 14: 211-220. [Medline]

65) Viebig RF, Pastor-Valero M, Scazufca M, et al.: Fruit and vegetable intake among low income elderly in the city of São Paulo, Southeastern Brazil. Rev Saude Publica, 2009, 43: 806-813. [Medline] [CrossRef]

66) Jaime PC, Machado FM, Westphal MF, et al.: [Nutritional education and fruit and vegetable intake: a randomized community trial]. Rev Saude Publica, 2007, 41: 154-157. [Medline] [CrossRef]

67) Scocco P, Rapattoni M, Fantoni G: Nursing home institutionalization: a source of eustress or distress for the elderly? Int J Geriatr Psychiatry, 2006, 21: 281-287. [Medline] [CrossRef]

68) Prieto-Flores ME, Forjaz MJ, Fernandez-Mayoralas G, et al.: Factors associated with loneliness of noninstitutionalized and institutionalized older adults. J Aging Health, 2011, 23: 177-194. [Medline] [CrossRef]

69) Zaninotto P, Falaschetti E, Sacker A: Age trajectories of quality of life among older adults: results from the English Longitudinal Study of Ageing. Qual Life Res, 2009, 18: 1301-1309. [Medline] [CrossRef]

70) Frumi C, Celich KL: An elderly's view of the act of getting old and the death. RBCEH, 2006, 3: 92-100. 